\title{
Potencial do estrato arbóreo-arbustivo de Cerrado Sensu Stricto para fins medicinais
}

\author{
Potential of the Cerrado Sensu Stricto arborous-arbustive structure for medical purposes
}

Potencial de la estructura arburosa-arbustiva de Cerrado Sensu Estricto para fines médicos

Getulio Rodrigues Pereira Paiva ORCID: https://orcid.org/0000-0002-6984-5648 Instituto Federal de Brasília, Brasil E-mail: getuliorppaiva@gmail.com

Ilvan Medeiros Lustosa Junior ORCID: https://orcid.org/0000-0002-3873-737X Instituto Federal de Brasília, Brasil E-mail: Ilvan.junior@ifb.edu.br

Fabiana Piontekowski Ribeiro ORCID: https://orcid.org/0000-0002-5375-6368 Universidade de Brasília, Brasil E-mail: fabiana.ribeiro@unb.br Uidemar Moraes Barral ORCID: https://orcid.org/0000-0002-6876-2883 Universidade de Brasília, Brasil E-mail: uidemarmorais@gmail.com

Leonardo Ferreira Guedes

ORCID: https://orcid.org/0000-0003-2655-8101 Instituto Federal de Brasília, Brasil

E-mail: leonardoferreiraguedes@gmail.com

Sibelle Oliveira Pinto

ORCID: https://orcid.org/0000-0002-8517-1284 Instituto Federal de Brasília, Brasil E-mail: sibelleoliveira@gmail.com

Stefany Lorrane Gomes dos Santos ORCID: https://orcid.org/0000-0002-5042-5029 Instituto Federal de Brasília, Brasil

E-mail: stefanylorrane180@gmail.com

Glendo Henrique de Castro Oliveira ORCID: https://orcid.org/0000-0002-4336-423X Universidade de Brasília, Brasil

E-mail: glendohenrique@gmail.com

Mikaela Soares Silva Cardoso ORCID: https://orcid.org/0000-0001-9061-0782 Universidade de Brasília, Brasil E-mail: mika.floresta@gmail.com

Viviane Evangelista dos Santos Abreu ORCID: https://orcid.org/0000-0003-1523-2149 Instituto Federal de Brasília, Brasil E-mail: viviane.abreu@ifb.edu.br Elisa Pereira Bruziguessi

ORCID: https://orcid.org/0000-0003-3419-0749 Instituto Federal de Brasília, Brasil

E-mail: elisa.bruziguessi@ifb.edu.br

Raphael Maia Aveiro Cessa

ORCID: https://orcid.org/0000-0002-4905-6959 Instituto Federal de Brasília, Brasil E-mail: raphael.cessa@ifb.edu.br

\section{Resumo}

A vegetação do Cerrado apresenta alta biodiversidade e os conhecimentos tradicionais e científicos sobre as plantas para fins medicinais são importantes na consolidação do uso terapêutico, uma vez que são empregadas no tratamento e na cura de enfermidades há milhares de anos. Com base na relevância da temática, esse estudo objetiva avaliar o potencial medicinal das espécies de plantas do estrato arbóreo-arbustivo em área de cerrado sensu stricto. Para isso, foi realizado um levantamento florístico-fitossociológico na área de conservação do campus Planaltina do Instituto Federal de Brasília (IFB). Em cada parcela amostrada foram identificados e mensurados todos os indivíduos arbóreoarbustivos com DAB (diâmetro tomado a $30 \mathrm{~cm}$ do nível da base) e DAP (diâmetro a altura do peito) igual ou superior 
a $5 \mathrm{~cm}$ e altura total (Ht). Foram identificados 943 indivíduos, de 70 espécies, 34 famílias botânicas em 56 gêneros. Após análise fitossociológica da comunidade amostrada, foram selecionadas as 10 espécies de maior relevância ecológica e assim foi realizado um levantamento bibliográfico a fim de analisar o potencial destas espécies para fins medicinais. Foi constatado que $90 \%$ das espécies de maior relevância no índice de valor de importância no Parque Distrital Colégio Agrícola de Brasília, são de uso medicinal consagrado pela literatura e pelo saber tradicional.

Palavras-chave: Inventário florestal; Recurso terapêutico; Espécies potenciais.

\begin{abstract}
The Cerrado vegetation has high biodiversity and traditional and scientific knowledge about plants for medicinal purposes is important in consolidating therapeutic use, since they have been used in the treatment and cure of diseases for thousands of years. Based on the relevance of the theme, this study aims to evaluate the medicinal potential of species of plants in the arboreal-shrub stratum in a cerrado sensu stricto area. For this, a floristic-phytosociological survey was carried out in the conservation area of the Planaltina campus of the Federal Institute of Brasília (IFB). In each sampled plot, all tree-shrub individuals with DAB (diameter taken at $30 \mathrm{~cm}$ from the base level) and DBH (diameter at breast height) equal to or greater than $5 \mathrm{~cm}$ and total height $(\mathrm{Ht})$ were identified and measured. 943 individuals were identified, from 70 species, 34 botanical families in 56 genera. After phytosociological analysis of the sampled community, the 10 selected species of greater ecological relevance and thus a bibliographic survey was carried out in order to analyze the potential of these species for medicinal purposes. It was found that $90 \%$ of the most important species in the importance value index in the Parque Agricola Colégio Agrícola de Brasília, are of medicinal use consecrated by literature and traditional knowledge.
\end{abstract}

Keywords: Forest inventory; Therapeutic resource; Potential species.

\title{
Resumen
}

La vegetación del Cerrado tiene una alta biodiversidad y el conocimiento tradicional y científico sobre las plantas con fines medicinales es importante para consolidar el uso terapéutico, ya que se han utilizado en el tratamiento y cura de enfermedades durante miles de años. Con base en la relevancia del tema, este estudio tiene como objetivo evaluar el potencial medicinal de especies de plantas en el estrato arbustivo-arbóreo en un área de cerrado sensu stricto. Para ello, se realizó un relevamiento florístico-fitosociológico en el área de conservación del campus Planaltina del Instituto Federal de Brasilia (IFB). En cada parcela muestreada, se identificaron y midieron todos los individuos de árboles-arbustos con DAB (diámetro tomado a $30 \mathrm{~cm}$ del nivel de la base) y DAP (diámetro a la altura del pecho) igual o mayor a $5 \mathrm{~cm}$ y altura total $(\mathrm{Ht})$. Se identificaron 943 individuos, de 70 especies, 34 familias botánicas en 56 géneros. Después del análisis fitosociológico de la comunidad muestreada, seleccionamos las 10 especies de mayor relevancia ecológica por lo que se realizó un relevamiento bibliográfico con el fin de analizar el potencial de estas especies con fines medicinales. Se encontró que el $90 \%$ de las especies más relevantes en el índice de valor de importancia en el Parque Agrícola Colégio Agrícola de Brasília, son de uso medicinal consagrado por la literatura y los saberes tradicionales.

Palabras clave: Inventario forestal; Recurso terapêutico; Especies potenciales.

\section{Introdução}

O Cerrado é o segundo maior bioma da América do Sul, com uma área de $2.036 .448 \mathrm{~km}^{2}$, representando cerca de 23,9\% do território do país (IBGE, 2020). A sua extensão abrange 12 estados brasileiros e se apresenta como um dos biomas mais relevantes na conservação da biodiversidade, sendo detentor de $5 \%$ de toda a diversidade do planeta e abriga $30 \%$ dos diversos seres vivos identificados no Brasil (EMBRAPA, 2020).

O Bioma em questão possui como uma das suas principais características uma composição florística rica e diversa, consistindo num fator de extrema importância na manutenção dos recursos naturais renováveis (Strassburg et al., 2017). Nesse sentido, o componente vegetacional funciona como um manto protetor dos recursos naturais, tendo em vista que a sua distribuição e densidade definem o estado de conservação do ambiente (Melo et al., 2011).

A estrutura do Cerrado se apresenta como um mosaico florístico formado por fitofisionomias que vão de formações florestais “(Mata Ciliar, Mata de Galeria)”, Savânicas “(Denso, Típico, Ralo e Rupestre)”, e Campestre "(Campo Sujo, Campo Rupestre e Campo Limpo)" (Borghetti et al., 2019). Neste contexto, o cerrado sensu stricto abrange as fitofisionomias de cerrado denso, cerrado típico, cerrado ralo e cerrado rupestre e é caracterizado pela presença de árvores baixas, inclinadas, tortuosas, com ramificações irregulares e retorcidas, e geralmente com evidências de queimadas. Os arbustos e subarbustos 
encontram-se espalhados, com algumas espécies apresentando órgãos subterrâneos perenes (xilopódios), que permitem a rebrota após queima ou corte (Borghetti et al., 2019).

Diante desse vasto cenário florístico, acredita-se que dentre o rol de espécies já identificadas que compõem este bioma ainda é incipiente a discussão acerca dos usos e indicações terapêuticas de plantas que possuem em sua formulação alguma propriedade medicinal, já disseminada e popularmente usada para combater uma ou mais patologias (Senegalia et al., 2020). O uso de plantas medicinais mostra prevalência como forma de Prática Integrativa e Complementar (PIC) (Oliveira et al., 2012). Porém, a importância dessa temática é fundamentada no aumento na recomendação de práticas de plantas medicinais e de fitoterápicos como alternativas apoiadas por políticas no âmbito do Sistema Único de Saúde (SUS) (Zeni et al., 2017).

Define-se como planta medicinal o vegetal que tem seu princípio ativo evidenciado farmacologicamente e incluso na farmacopeia (Lorenzi \& Matos, 2008). De acordo com Rodrigues (2010), o conceito de plantas medicinais está relacionado à presença de substâncias bioativas e com propriedades terapêuticas, profiláticas que melhoram a qualidade de vida. Não obstante, a Organização Mundial da Saúde (OMS, 2021) define que as plantas medicinais são todas aquelas que contêm em um ou mais de seus órgãos substâncias que podem ser utilizadas com propósitos terapêuticos ou que sejam precursoras de semisíntese químico-farmacêutica. A Agência Nacional de Vigilância Sanitária define planta medicinal como uma espécie vegetal, cultivada ou não, utilizada com propósitos terapêuticos e, ainda traz a luz, o conceito de derivado vegetal como o produto da extração de planta medicinal in natura ou da droga vegetal podendo ocorrer na forma de extrato, tintura, alcoolatura, óleo fixo e volátil, cera, exsudato e outros derivados (ANVISA, 2014).

$\mathrm{O}$ uso de plantas medicinais na cura de enfermidades é uma forma antiga de tratamento que tem como princípios as informações provenientes de sucessivas gerações (Ceolin et al., 2011). O primeiro registro de estudos relacionados ao uso de centenas de plantas no tratamento de moléstias foi a obra chinesa "A grande fitoterapia" (Pen Ts'ao), cerca de 2800 a.C. escrita por Shen-Nong. Entretanto, as plantas medicinais foram objetos de estudos em praticamente todas as antigas civilizações (Monteiro \& Brandelli, 2017).

Partindo desse pressuposto, a identificação de espécies de plantas do cerrado sensu stricto e divulgação dos possíveis efeitos provocados pelo contato humano com as mesmas é fundamental para a manutenção e conservação do bioma. Por garantir a qualidade de vida e valorização dos conhecimentos tradicionais à comunidade científica, tendo em vista que a divulgação do conhecimento popular associado a essa prática pode contribuir nos aspectos de segurança, qualidade e eficácia na saúde pública brasileira (Dias \& Laureano, 2009).

Diante do exposto, o presente estudo teve como objetivo avaliar e quantificar no componente arbóreo-arbustivo na área de conservação do Parque Distrital Colégio Agrícola de Brasília a presença de espécies de plantas medicinais em área de cerrado sensu stricto e constatar esta finalidade em literatura especializada.

\section{Metodologia}

O estudo foi realizado na área de conservação do Parque Distrital Colégio Agrícola de Brasília nas limitações do Instituto Federal de Educação, Ciência e Tecnologia de Brasília - IFB, Campus Planaltina, Planaltina- DF, 15³9’24.70”S $47^{\circ} 41^{\prime} 40.58^{\prime \prime} \mathrm{O}$. A área de estudo caracteriza-se como de vegetação predominantemente de cerrado sensu stricto, muito embora haja a presença de demais formações vegetacionais e outras fitofisionomias, com aproximadamente 1.039,63 hectares, altitude de 950 a 1.150 metros acima do nível do mar, região hidrográfica do Paraná, bacia hidrográfica do Rio São Bartolomeu.

O clima da região é do tipo tropical chuvoso segundo a classificação de Köppen, com duas estações climáticas bem definidas: seca, entre os meses de maio a setembro, e chuvosa, entre outubro e abril. A média anual de precipitação observada 
nos últimos quarenta anos foi de 1345,8 mm, o início da estação chuvosa acontece a partir da segunda quinzena do mês de setembro, com registro de precipitação média de 36,5 mm (Silva et al., 2017). Quanto aos aspectos edáficos, de acordo com a Reatto et al. (2004), há predominância de solos das classes: Latossolo Vermelho, Latossolo Vermelho-Amarelo, Cambissolo Háplico, Argissolo Vermelho-Amarelo, e Neossolo Quartzarênico nesta região do Distrito Federal.

O levantamento das espécies do estrato arbóreo-arbustivo para avaliação do potencial com fins medicinais foi realizado por meio de processo de amostragem. Foram instaladas $10(\mathrm{dez})$ parcelas de 20 x 50 (100 $\left.\mathrm{m}^{2} \mathrm{cada}\right)$ que totalizou uma área amostrada de 1 ha. Em cada parcela foram amostrados todos os indivíduos arbóreo-arbustivos com $5 \mathrm{~cm}$ de diâmetro ao nível do solo (30 cm de altura), conforme a recomendação do manual de parcelas permanentes (Felfili; Carvalho \& Haidar, 2005) e pelo Serviço Florestal Brasileiro (SFB, 2019), sendo desconsiderados no levantamento todos os indivíduos mortos cujo tronco principal não possuía tecidos vivos ou folhas, mesmo no auge da estação chuvosa. A suficiência amostral da representatividade da diversidade de espécies nas parcelas foi analisada por meio da curva de acumulação, pelo método de rarefação pelo pacote R (Gotelli \& Colwell, 2001).

As parcelas foram dispostas de acordo o método de amostragem casual simples, uma vez que a distribuição das mesmas foi de forma aleatória, evitando as áreas ocupadas por pastagem, construções, vias e as demais formações vegetacionais que não se caracterizam como tipicamente de cerrado sensu stricto. Após a instalação de cada parcela (Figura 1), foram tomadas as coordenadas geográficas das suas poligonais com GPS modelo Garmin Etrex e fincados vergalhões de ferro em suas arestas a fim de controlar o local exato e a visualização dos quatro vértices das parcelas.

Figura 1. Mapa de localização e distribuição das parcelas

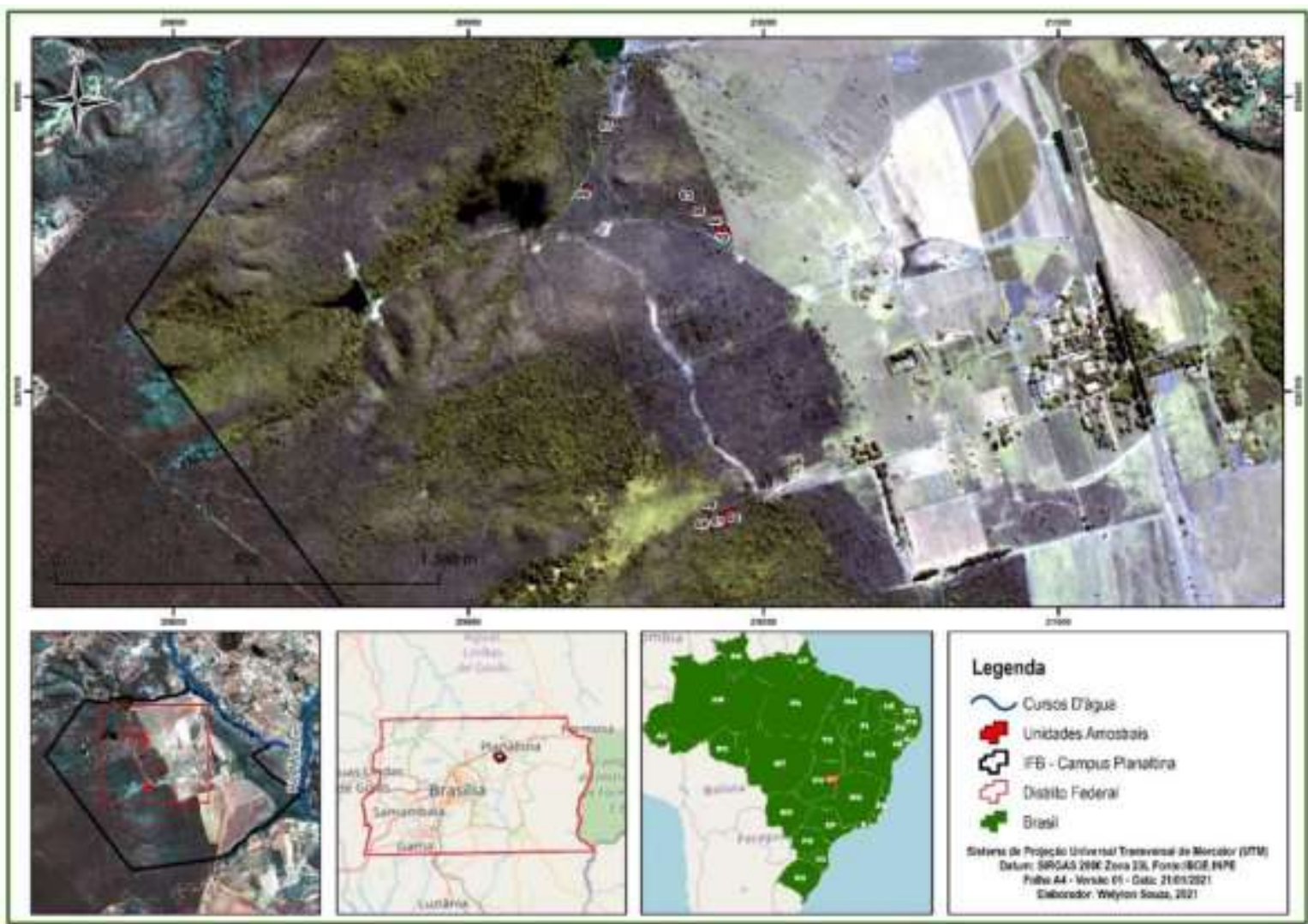

Fonte: Autores, (2021). 
A identificação das espécies em campo foi feita a partir da observação das características botânicas e dendrológicas, com auxílio de chaves de identificação de espécies do cerrado sensu stricto (Silva Júnior, 2012) e organizadas de acordo o Angiosperm Phylogeny Group IV (Chase at al., 2016). Cada indivíduo amostrado foi identificado e marcado com placa metálica numerada. Quando não possível o reconhecimento das espécies, foram realizadas consultas à bibliografia especializada ou montadas exsicatas com materiais botânicos para posterior envio e comparações com materiais depositados no Herbário da Universidade de Brasília (UnB).

A análise florística-fitossociológica foi possível por meio dos parâmetros fitossociológicos baseados na abundância (número de indivíduos de cada espécie), frequência (número de parcelas em que uma espécie ocorre), e área basal (área do tronco na altura em que o diâmetro é medido). Além destes, foram analisados os índices de valor de importância (IVI), cobertura (IVC), índice de diversidade de Shannon (H') e Pielou (J). Todos os parâmetros são apresentados abaixo:

1) Abundância

$n$

Refere-se ao número de árvores por espécie amostradas na parcela

2) Densidade

- Absoluta

$D A=\frac{n}{\text { Area }}$

Representa o número de árvores por unidade de área (hectare).

- Relativa

$D R=\frac{n}{N} * 100$

Representa a relação entre a participação das espécies e o número total de árvores.

3) Frequência

- Absoluta

$F A=\frac{p i}{P} * 100$

Proporção entre o número de parcelas em que certa espécie ocorre e o número total de parcelas alocadas

- Relativa

$F R=\frac{F A_{i}}{I F A} * 100$

Refere-se à relação da frequência absoluta de determinada espécie e o somatório das frequências absolutas de todas as espécies.

4) Dominância

- Absoluta

$D o A=\frac{g i}{\text { Area }} * 100$

Dominância Relativa (DoA) representa área basal total ( $g i)$ de uma determinada espécie por unidade de área (hectare)

- Relativa

$D o R=\frac{g i}{G} * 100$ 
Dominância Relativa (DoR) representa a porcentagem da área basal de uma determinada espécie ( $g i$ ) em relação a área basal de todas as espécies amostradas $(\mathrm{G})$, o somatório das áreas basais individuais), ambas calculadas por unidade de área.

5) Índice de Valor de Importância (IVI) - Curtis e Mclntosh (1951)

$V I=D R+D o R+F R$

Nível de importância de cada espécie na comunidade

6) Índice de Valor de Cobertura (IVC)

$V C=D R+D o R$

Taxa de ocupação de indivíduos e biomassa dentro da comunidade

7) Índice de diversidade Shannon-Wiener e o índice de equidade de Pielou (Krebs, 2007).

Em que: $n=$ número de indivíduos de uma determinada espécie; $N=$ número total de indivíduos; $P i=$ número de parcelas (unidades amostrais) com ocorrência da espécie $i ; P=$ número total de parcelas (unidades amostrais) na amostra; $F A i$ = Frequência absoluta de uma determinada espécie. $\sum F A=$ somatório das frequências absolutas de todas as espécies amostradas.

Para fins de levantamento bibliográfico do potencial medicinal das espécies arbórea-arbustivas, foi adotado como critério a seleção das 10 espécies de maior valor de importância na comunidade. Assim, por meio de pesquisas em literatura especializada, foram elencados os principais tratamentos das enfermidades tratadas, usos, indicações, partes usadas e pesquisas em desenvolvimento. A pesquisa foi de natureza quali-quantitativa o que envolvem a interpretação dos dados e os métodos mistos (Pereira et al., 2018). Quantitativo porque foi realizado o levantamento das espécies em campo, e qualitativo porque através do inventário pode-se classificar as características das espécies com potenciais indicações para uso medicinal.

\section{Resultados e Discussão}

A curva de acumulação pelo método de rarefação foi construída tendo como base a diversidade e o número de indivíduos por parcela, logo, esta curva representa a proporção entre o número de espécies esperado caso se faça um maior esforço amostral ao alocar-se mais parcelas na área. Nesse sentido, é possível analisar a riqueza de espécies em níveis comparáveis de esforço amostral (Gotelli \& Colwell, 2001).

Novas espécies podem fazer parte da amostra caso fossem alocadas mais parcelas a fim de representar a área em questão, como pode ser observado na curva da Figura 2. Porém, a não estabilização da curva obtida pelo esforço amostral é um comportamento esperado quando se trata de estudos relacionados à vegetação tropical que, segundo Schilling et al. (2012), a suficiência amostral ideal por meio da estabilidade completa dessa curva é praticamente impossível de ser alcançada quando realizada por métodos randomizados e adotando amostragem da vegetação.

Ao analisar a tendência da curva de acumulação empregando o método de rarefação em cerrado sensu stricto, Sampaio et al. (2018), relatam que o comportamento da assíntota da curva de acúmulo de espécies (e consequente suficiência amostral) só é atingida se a distribuição espacial das espécies for aleatória, o que não é o caso das áreas de vegetação natural, onde a agregação é uma característica intrínseca. 
Figura 2. Curva de acumulação de espécies por rarefação baseada em abundância de espécies arbóreo-arbustivas presentes no cerrado sensu stricto no Parque Distrital Colégio Agrícola de Brasília.

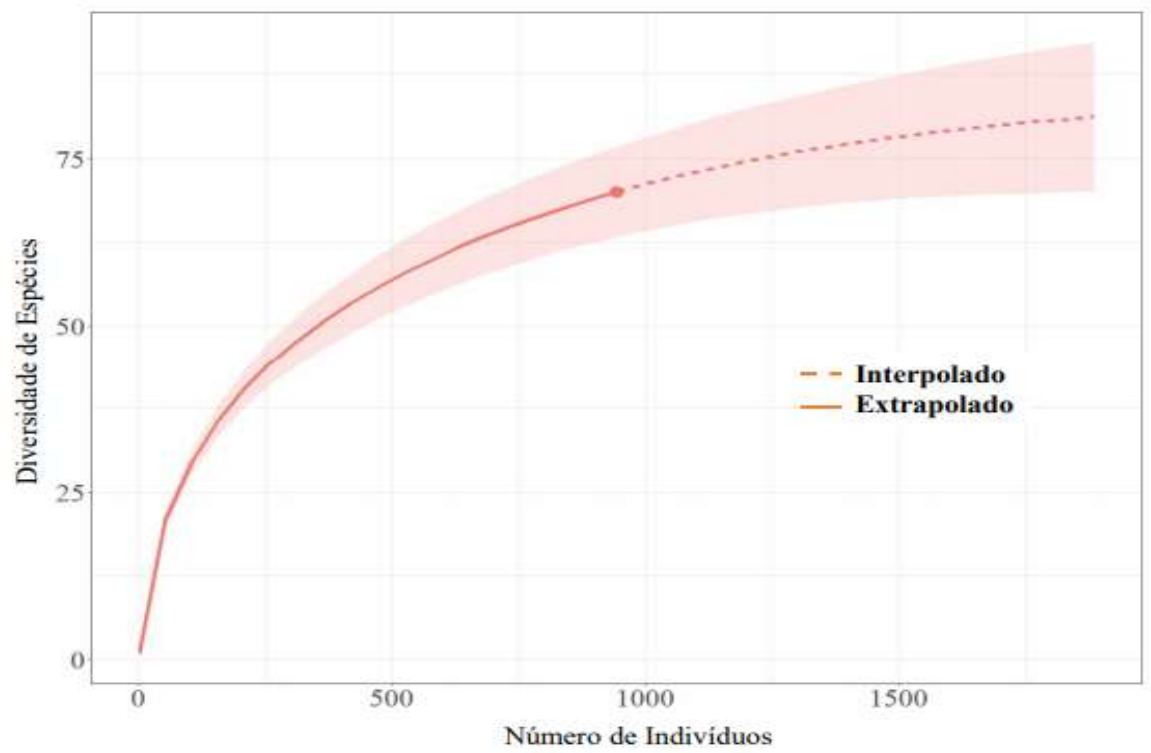

Fonte: Autores, (2021).

O levantamento florístico-fitossociológico em área de cerrado sensu stricto no Parque Distrital Colégio Agrícola de Brasília resultou em 943 indivíduos, distribuídos em 70 espécies, pertencentes a 34 famílias botânicas, em 56 gêneros do estrato arbóreo-arbustivo. Essa amostragem correspondeu a uma área basal total de 39,02 m²/ha, com diâmetro médio de 19,81 cm e uma altura média de 5, 12 metros nas 10 parcelas instaladas na área. Na Tabela 1 são apresentadas as dez mais importantes espécies, segundo a amostragem realizada.

Tabela 1. Parâmetros fitossociológicos das 10 espécies de maior VI amostradas em cerrado sensu stricto no Parque Distrital Colégio Agrícola de Brasília, Planaltina-DF.

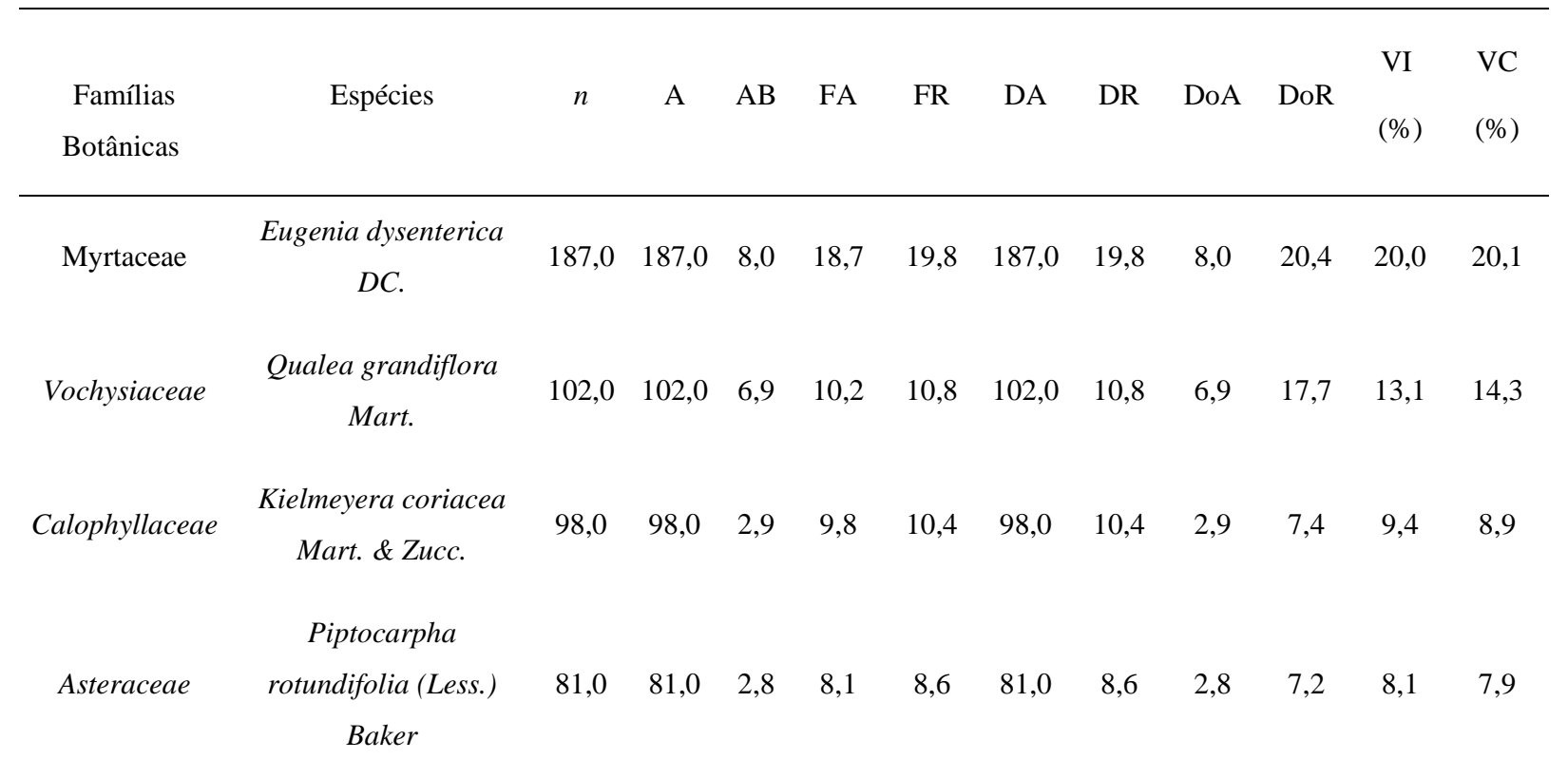




\begin{tabular}{|c|c|c|c|c|c|c|c|c|c|c|c|c|}
\hline Vochysiaceae & $\begin{array}{c}\text { Qualea parviflora } \\
\text { Mart. }\end{array}$ & 55,0 & 55,0 & 2,0 & 5,5 & 5,8 & 55,0 & 5,8 & 2,0 & 5,0 & 5,6 & 5,4 \\
\hline Annonaceae & $\begin{array}{c}\text { Xylopia aromática } \\
\text { (Lam.) }\end{array}$ & 49,0 & 49,0 & 1,4 & 4,9 & 5,2 & 49,0 & 5,2 & 1,4 & 3,5 & 4,6 & 4,3 \\
\hline Fabaceae & $\begin{array}{c}\text { Stryphnodendron } \\
\text { adstringes (Mart.) } \\
\text { Coville }\end{array}$ & 33,0 & 33,0 & 2,4 & 3,3 & 3,5 & 33,0 & 3,5 & 2,4 & 6,1 & 4,4 & 4,8 \\
\hline $\begin{array}{c}\text { Melastomatace } \\
\text { ae }\end{array}$ & $\begin{array}{c}\text { Miconia burchellii } \\
\text { Triana }\end{array}$ & 37,0 & 37,0 & 1,0 & 3,7 & 3,9 & 37,0 & 3,9 & 1,0 & 2,6 & 3,5 & 3,3 \\
\hline Caryocaraceae & $\begin{array}{c}\text { Caryocar brasiliense } \\
\text { Cambess. }\end{array}$ & 21,0 & 21,0 & 1,5 & 2,1 & 2,2 & 21,0 & 2,2 & 1,5 & 3,8 & 2,7 & 3,0 \\
\hline Malpighiaceae & $\begin{array}{l}\text { Byrsonima crassifólia } \\
\text { (L.) Kunth. }\end{array}$ & 29,0 & 29,0 & 0,7 & 2,9 & 3,1 & 29,0 & 3,1 & 0,7 & 1,8 & 2,7 & 2,5 \\
\hline
\end{tabular}

Fonte: Autores, (2021).

As 10 espécies de maior VI representaram 70,24\% de todos os indivíduos amostrados e 75,65\% da área basal na amostragem. Não obstante, as espécies mais representativas pelo VI também apresentaram os maiores VC. De acordo com Rêgo et al. (2015), esse resultado aponta que a densidade e a dominância representaram eficientemente a estrutura da vegetação analisada, constatando que a frequência, de forma geral, está associada à densidade das espécies.

O índice de diversidade de Shannon-Wiener (H') e o valor de equabilidade de Pielou (J') da comunidade foram, respectivamente, 3,094 e 0,73. Logo, a diversidade de Shannon neste estudo está coerente com estudos similares em cerrado sensu stricto de outras regiões do bioma que variam de 3,0 a 3,8 (Felfili et al., 2004; Lisita, 2008). Ao comparar 16 áreas de cerrado sensu stricto, Lopes et al. (2011) definiram que o padrão de diversidade para fitofisionomia do Brasil Central aponta variação no índice de Shannon de 3,02 a 3,69.

A partir da equabilidade de Pielou pode-se constatar que a distribuição da abundância das espécies é equilibrada, uma vez que foi representada em $73 \%$ da diversidade máxima da área amostrada (Magurran, 1988). A obtenção e discussão sobre informações relacionadas ao número de espécies, densidade arbórea, área basal e o índice de diversidade de Shannon são úteis e devem ser utilizados para essas comparações e aferições de grau de conservação de áreas de Cerrado (Rios et al., 2020).

A seleção das 10 espécies de maior valor de importância (Tabela 1), a partir do levantamento florísticofitossociológico, possibilitou a realização de consultas à bibliografia especializada e subsidiou a obtenção de informações acerca do potencial de uso medicinal (Tabela 2). 
Tabela 2. Levantamento bibliográfico de indicações para uso medicinal das 10 espécies de maior VI amostradas em cerrado sensu stricto no Parque Distrital Colégio Agrícola de Brasília, Planaltina-DF.

\begin{tabular}{|c|c|c|c|}
\hline Espécies & $\begin{array}{c}\text { Nome } \\
\text { Popular/ } \\
\text { Hábito }\end{array}$ & $\begin{array}{l}\text { Parte } \\
\text { usada }\end{array}$ & Indicações \\
\hline $\begin{array}{l}\text { Eugenia dysenterica } \\
\qquad D C .\end{array}$ & $\begin{array}{l}\text { Cagaita / } \\
\text { Arbóreo }\end{array}$ & $\begin{array}{l}\text { Casca, } \\
\text { Frutos e } \\
\text { Folhas }\end{array}$ & $\begin{array}{l}\text { Casca e folhas possuem ação antidiarreica, cicatrizante, antioxidante, } \\
\text { moluscicida. Apresenta potencial antibacteriano e antifúngico (Silva Junior, } \\
\text { 2012; Pereira \& Cunha, 2015; Queiroz, 2015; Silva; Rabelo \& Enoque, 2015). }\end{array}$ \\
\hline $\begin{array}{l}\text { Qualea grandiflora } \\
\text { Mart. }\end{array}$ & $\begin{array}{c}\text { Pau-terra / } \\
\text { Arbóreo }\end{array}$ & $\begin{array}{l}\text { Folhas e } \\
\text { Cascas }\end{array}$ & $\begin{array}{l}\text { As cascas são antissépticas. As folhas são indicadas para } \\
\text { tratar diarreias com sangue, cólicas intestinais, dores estomacais, amebíase e } \\
\text { inflamações em geral (Aguiar \& Barros 2012; Silva Junior, 2012; Silva; Rabelo } \\
\text { \& Enoque, 2015). }\end{array}$ \\
\hline $\begin{array}{l}\text { Kielmeyera coriacea } \\
\text { Mart. }\end{array}$ & $\begin{array}{l}\text { Pau-santo / } \\
\text { Arbóreo }\end{array}$ & $\begin{array}{l}\text { Folhas e } \\
\text { Cascas }\end{array}$ & $\begin{array}{l}\text { Emoliente. A casca é considerada tônica e emoliente, sendo utilizada para tratar } \\
\text { dores de dente. As folhas possuem propriedades emolientes (Silva Junior, 2012; } \\
\text { Silva; Rabelo \& Enoque, 2015). }\end{array}$ \\
\hline $\begin{array}{l}\text { Piptocarpha } \\
\text { rotundifolia (Less.) } \\
\text { Baker }\end{array}$ & $\begin{array}{l}\text { Cinzeiro / } \\
\text { Arbóreo }\end{array}$ & $\begin{array}{l}\text { Flores e } \\
\text { Folhas }\end{array}$ & $\begin{array}{l}\text { As folhas e flores são usadas como enérgicos, e também, como antisséptico, } \\
\text { anti-inflamatório e antidiarreico (Silva, Rabelo; Enoque, 2015). }\end{array}$ \\
\hline $\begin{array}{l}\text { Qualea parviflora } \\
\text { Mart. }\end{array}$ & $\begin{array}{l}\text { Pau-terrinha } \\
\text { / Arbóreo }\end{array}$ & $\begin{array}{l}\text { Folhas e } \\
\text { entrecasca }\end{array}$ & $\begin{array}{l}\text { As cascas e as folhas são utilizadas para tratamento de gastrite (Silva; Rabelo \& } \\
\text { Enoque, 2015; Vieira et al., 2015). }\end{array}$ \\
\hline $\begin{array}{l}\text { Xylopia aromática } \\
\text { (Lam.) }\end{array}$ & $\begin{array}{l}\text { Pimenta-de- } \\
\text { macaco / } \\
\text { Arbóreo }\end{array}$ & $\begin{array}{l}\text { Frutos, } \\
\text { folhas e } \\
\text { casca }\end{array}$ & $\begin{array}{l}\text { A casca do caule é utilizada como anti-inflamatório e trata problemas } \\
\text { digestivos. Apresenta propriedades afrodisíacas, tônico, vermífugo, febrífugo } \\
\text { entre outras (Silva Junior, 2012; Silva; Rabelo \& Enoque, 2015; Brandão, } \\
\text { 2019). }\end{array}$ \\
\hline $\begin{array}{l}\text { Stryphnodendron } \\
\text { adstringes (Mart.) } \\
\text { Coville }\end{array}$ & $\begin{array}{l}\text { Barbatimão } \\
\text { / Arbóreo }\end{array}$ & $\begin{array}{l}\text { Casca, } \\
\text { folhas e raiz }\end{array}$ & $\begin{array}{l}\text { É indicado no tratamento de hemorragias, diarreia, hemorroidas, para limpeza } \\
\text { de ferimentos e chá da raiz na forma de gotas contra conjuntivite, prevenir } \\
\text { queimaduras resultantes da radioterapia, antifúngico para tratar candidíase. } \\
\text { Acne e manchas de pele e calvície na fitocosmética (Aguiar \& Barros, 2012; } \\
\text { Silva Junior, 2012; Oliveira et al., 2012; Pereira \& Cunha, 2015; Alonso, 2016). }\end{array}$ \\
\hline $\begin{array}{l}\text { Miconia burchellii } \\
\text { Triana }\end{array}$ & $\begin{array}{l}\text { Pixirica / } \\
\text { Arbusto }\end{array}$ & Folhas & Citotóxica para células tumorais (Cunha et al., 2021). \\
\hline $\begin{array}{l}\text { Caryocar brasiliense } \\
\text { Cambess. }\end{array}$ & $\begin{array}{l}\text { Pequi / } \\
\text { Arbóreo }\end{array}$ & $\begin{array}{l}\text { Cascas, } \\
\text { folhas e } \\
\text { fruto }\end{array}$ & $\begin{array}{l}\text { A casca e as folhas são adstringentes. O óleo da castanha e } \\
\text { os caroços são utilizados para tratar asma, bronquite, coqueluche e resfriados. } \\
\text { Os caroços são considerados tônicos e afrodisíacos. As folhas são adstringentes } \\
\text { e estimulam a secreção da bile. Regulador de fluxo menstrual (Silva; Rabelo \& } \\
\text { Enoque, 2015). }\end{array}$ \\
\hline $\begin{array}{l}\text { Byrsonima crassifolia } \\
\quad \text { (L.) Kunth }\end{array}$ & $\begin{array}{l}\text { Murici / } \\
\text { Arbusto }\end{array}$ & $\begin{array}{c}\text { Folha, } \\
\text { Frutos e } \\
\text { Casca, raiz }\end{array}$ & $\begin{array}{l}\text { Alto teor de carotenoides, atividade antioxidante e antifúngica e antidepressiva } \\
\text { (Herrera-Ruiz et al., 2011; Brandão, 2019). }\end{array}$ \\
\hline
\end{tabular}

Fonte: Autores, (2021).

A Eugenia dysenterica (Cagaita) é a espécie que apresentou maior VI (Tabela 1). Junto com sua representatividade botânica, possui amplas propriedades medicinais, em que várias partes da árvore são utilizadas para cura de alguma 
enfermidade (Tabela 2). Além do poder farmacológico, essa espécie apresenta uso comercial dos seus frutos, madeira e óleos essenciais (Lago et al., 2011; Silva Junior, 2012; Queiroz, 2015; Pereira \& Cunha, 2015; Silva et al., 2015).

Em função do potencial terapêutico desta espécie, estudos relatam suas propriedades medicinais de várias formas e em várias partes das plantas. Lima et al. (2010) afirmam que as folhas podem ser usadas na forma de chá para tratar icterícia, distúrbios gástricos, diarréia e disenteria. Cardoso et al. (2011) constataram que folhas e frutos possuem ação cicatrizante, além de ajudar a melhorar possíveis desconfortos na bexiga e combate à prisão de ventre. Não obstante, estes autores também encontraram potencialidades das suas flores no uso do chá para tratar infecções renais e da bexiga e as cascas podem ser empregadas como substância diurética, adstringente e depurativa.

A Segunda espécie de maior VI foi a Qualea grandiflora, conhecida popularmente por Pau-terra (Tabela 1) e apresenta cascas que são conhecidas como antissépticas (Tabela 2). As folhas e cascas são indicadas para tratar problemas gástricos (Silva et al., 2017). O extrato hidroalcoólico bruto (HE) obtido da casca de Qualea grandiflora apresenta um efeito antiúlcera significativo em modelo induzido por úlcera (Hiruma-Lima et al., 2006). Também foram encontradas referências em que a espécie é utilizada para amebíase, cólicas intestinais, diarreias com sangue e dores estomacais (Pinheiro et al., 2019).

Além das propriedades apresentadas na Tabela 2, a espécie Kielmeyera coriacea (Pau-santo), com VI de 9,4 (Tabela 1), geralmente é utilizada na forma de garrafadas (vinho medicinal) e as suas folhas e cascas são empregadas na fabricação de corantes. Contudo, se faz presente na casca interna algumas propriedades antioxidantes, cicatrizantes, antifúngicas e antibacteriana (Santana, 2017). Banhos preparados com folhas, caule e cascas são utilizados no tratamento de enfermidades como malária, esquistossomose, leishmaniose (Pinheiro et al., 2019; Santana, 2017). Sua resina amarela tônica e emoliente extraída do caule é usada no tratamento de dores de dentes (Obici et al., 2008; Santana, 2017).

As folhas e cascas da Piptocarpha rotundifolia (Cinzeiro), com VI de 8,1 (Tabela 1), são indicadas para uso antisséptico, anti-inflamatório e antidiarreico (Silva; Rabelo \& Enoque, 2015). Já a quinta espécie de maior VI, Qualea parviflora (Pau-terrinha), apresenta uso medicinal para gastrite (Vieira et al., 2015). O extrato metanólico desta espécie apresenta efeito gastroprotetor relacionado ao aumento dos fatores de defesa da mucosa gástrica, e também apresenta atividade anti-Helicobacterpylori, efeito anti-hemorrágico e antioxidante, mas ausência de efeitos analgésicos, mutagênicos e tóxicos, agregando segurança ao seu uso (Mazzolin et al., 2010).

São encontradas na e cascas e frutos da Xylopia aromática (Pimenta-de-macaco) propriedades anti-inflamatórias quando maceradas e preparadas em forma de chá (Maroni 2006). Os frutos têm ação digestiva quando ingeridos na forma de chá decocto ou infuso após as refeições, as compressas com chá podem ser eficientes no tratamento de hemorroidas e, tanto as sementes, torradas e moídas, quanto a tintura do caule, possuem ação tônica e afrodisíaca (Pinheiro et al., 2019). Em outros estudos, como os de Silva Junior, (2012); Silva; Rabelo e Enoque (2015); Lorenze e Matos, (2008) e Brandão (2019), apontam o uso dos frutos como excitante, carminativo, tônico para o estômago, vermífugo, febrífugo e anti-hemorroida.

A Stryphnodendron adstringes (Barbatimão), possui atividade anti-inflamatória e antiedematosa, antiulcerogênica, antimicrobiana, cicatrizante, redução de queda de cabelo, clareador de pele (Alonso, 2016). A ingestão pode ocasionar estreitamento esofágico devido a adstringência (Vilarinho \& Garcia, 2017). Esta espécie é recomendada contra leucorreia, hemorragias, diarreia, hemorroidas, para limpeza de ferimentos e na forma de gotas contra conjuntivite, prevenção de queimaduras resultantes da radioterapia, além de ser indicado o chá de sua casca em uso externo para hemorragias uterinas, corrimento vaginal, feridas ulcerosas e para pele excessivamente oleosa (Aguiar \& Barros, 2012; Silva Junior, 2012; Oliveira et al, 2012; Pereira \& Cunha, 2015; Alonso, 2016).

A Miconia burchellii (Pixirica), dentre as 10 espécies de maior VI (Tabela 1) do estudo em questão, foi a única que não apresentou uso popular difundido (Tabela 2). No entanto, Cunha et al. (2021), ao estudarem as folhas de Miconia burchellii, encontraram atividade citotóxica contra quatro das cinco linhagens de células tumorais e leucemia em testes, não 
mostrando seletividade entre as linhas tumorais e não tumorais. Logo, o estudo contribuiu pela primeira vez para o conhecimento das características químicas e atividades biológicas da espécie de Miconia Burchellii Triana, sendo um indicativo de que mais pesquisas laboratoriais podem ser realizadas a fim de promover a difusão das peculiaridades farmacológicas da espécie.

A espécie Caryocar brasiliense (Pequi) apresenta um fruto muito apreciado na região centro-oeste do Brasil e dele podem ser extraídos a castanha, polpa e óleo. O chá da folha pode ser utilizado para fins medicinais no combate à bronquite, e o seu óleo pode ser usado tanto na comida para combater anemia quanto na formulação de garrafadas (vinho medicinal) com funcionalidades tônicas e afrodisíacas (Maroni, 2006). Além de importante recurso alimentar, seu uso auxilia no combate à rouquidão, dor de garganta, tosse, curativos e o óleo ajuda, por meio de compressas, a recomposição muscular, reumáticas e contusões. As folhas do pequi podem ser indicadas como estimulantes no sistema imunológico e protetor das mucosas, por apresentarem funções antioxidantes (Lorenzi \& Matos, 2008).

A Byrsonima crassifolia (Murici) foi a espécie que apresentou menor VI (Tabela 1) dentre as dez. Seu extrato inibe a ação de crescimento micelial dos fungos Fusarium solani e Sclerotinia scleotiorum, provavelmente relacionado aos constituintes químicos da planta, que possuem atividade antioxidante (Andrade et al., 2017). Além da ação fungicida encontrada no extrato etanólico da casca, o murici tem em suas sementes um poder anti-inflamatório que, quando usado de forma tópica, se mostra eficaz (Gutiérrez, 2016).

Os raios Ultravioleta B elevam os riscos de doenças relacionadas à pele, causando o fotoenvelhecimento e até mesmo o câncer, tornando indispensável o uso de fotoquimioprotetores. Estudos realizados por Almeida et al. (2019) atestam que constituintes químicos da folha de Byrsonima crassifolia é um eficiente protetor solar quando testados em animais, em que se observou o aumento da atividade antioxidante da pele e consequentemente à prevenção do fotoenvelhecimento. Contudo, os extratos da parte aérea ainda apresentam efeitos antidepressivos e outras atividades farmacológicas como ansiolíticos, sedativo, anticonvulsionante (Herrera-Ruiz et al., 2011).

\section{Considerações Finais}

As instituições técnico-científicas que se baseiam em princípios agroecológicos podem promover a discussão sobre o potencial medicinal das espécies do Cerrado, além de consolidar estratégias de manejo sustentável e recomendar o uso múltiplo destas, promovendo a conservação e manutenção dos serviços ecossistêmicos.

Dessa forma, cabe ressaltar que além das informações apresentadas neste trabalho é relevante propor uma forma de sistematizar os estudos das áreas circunvizinhas para manejo consciente dos recursos fitoterápicos. Uma vez que outras plantas do Cerrado que não foram contempladas nesse estudo podem apresentar potencial medicinal e serem fundamentais na promoção da conservação ecológica e difusão do conhecimento tradicional.

A conservação das matrizes para o manejo sustentável do Parque Distrital Colégio Agrícola de Brasília, a partir do envolvimento das comunidades circunvizinhas, contribui para a valorização dos seus conhecimentos tradicionais no que se refere ao uso medicinal. Assim, é interessante propor discussões sobre essa temática entre a comunidade acadêmica, comunidades tradicionais e o Centro de Referência em Práticas Integrativas em Saúde - CERPIS (Farmácia Viva - SUS) através do projeto de promoção de segurança nos usos etnomedicinais.

Para fins de direcionamentos, recomenda-se a promoção de rodas de conversas tendo como pauta a temática relacionada à fitoterapia do Cerrado, a confecção de material didático sobre práticas de manejo sustentável de cascas e frutos nativos e a discussão sobre os iminentes riscos de toxicidade quanto ao uso inadequado das espécies. 


\section{Referências}

Aguiar, L. C. G. G., \& Barros, R. F. M. (2012). Plantas medicinais cultivadas em quintais de comunidades rurais no domínio do cerrado piauiense (Município de Demerval Lobão, Piauí, Brasil). Revista Brasileira de Plantas Medicinais, 14(3), 419-434.

Almeida, V. D. S. S., Maranhão, M. F. C., Vasconcelos, A. C. S. L., Florentino, J. V. P., Barros, W. C., Rocha, R. B., \& do Carmo, M. S. (2019). Propriedades farmacológicas de Byrsonima crassifolia (L.) Kunt. Revista de Investigação Biomédica, 10(3), $280-289$.

Alonso, J. (2016). Tratado de Fitofármacos e Nutracêuticos [Tradução Luciano Prado da Silva, Maria Edith Barbagelata et al]. São Paulo: Ac Farmacêutica.

Andrade, B. S., Matias, R., Corrêa, B. O., Oliveira, A. K. M., Guidolin, D. G. F., \& Roel, A. R. (2018). Fitoquímica, potencial antioxidante e antifúngico de Byrsonima crassifolia no controle de fitopatógenos de solo. Brazilian Journal of Biology, 78(1), 140-146.

ANVISA. Agência nacional de vigilância Sanitária (2014). Resolução da diretoria colegiada. RDC

https://bvsms.saude.gov.br/bvs/saudelegis/anvisa/2014/rdc0026_13_05_2014.pdf

Borghetti, F., Barbosa, E., Ribeiro, L., Ribeiro, J. F., \& Walter, B. M. T. (2019). South American Savannas. Savanna Woody Plants and Large Herbivores, 77122 .

Brandão, M. G. L. (2018). Plantas úteis e medicinais na obra de Frei Vellozo. (2 ${ }^{\mathrm{a}}$ ed.), 3I Editora.

Cardoso, L. M., Martino, H. S. D., Moreira, A. V. B., Ribeiro, S. M. R., \& Pinheiro-Sant'Ana, H. M. (2011). Cagaita (Eugenia dysenterica DC.) of the Cerrado of Minas Gerais, Brazil: Physical and chemical characterization, carotenoids and vitamins. Food Research International, 44(7), $2151-2154$.

Ceolin, T., Heck, R. M., Barbieri, R. L., Schwartz, E., Muniz, R. M., \& Pillon, C. N. (2011). Plantas medicinais: transmissão do conhecimento nas famílias de agricultores de base ecológica no Sul do RS. Revista da Escola de Enfermagem da USP, 45(1), 47-54.

Chase, M. W., Christenhusz, M. J. M., Fay, M. F., Byng, J. W., Judd, W. S., Soltis, D. E., \& Stevens, P. F. (2016). An update of the Angiosperm Phylogeny Group classification for the orders and families of flowering plants: APG IV. Botanical Journal of the Linnean Society, 181(1), 1-20.

Cunha, G. O. S., da Silva, D. M., dos Santos, M. L., de Moraes Filho, M. O., do Ó Pessoa, C., de Jesus Guimarães, C., \& Menezes, A. C. S. (2021). Chemical constituents and cytotoxic activity of Miconia burchellii Triana (Melastomataceae) leaves. South African Journal of Botany, 137, 345-350.

Curtis, J. T., \& McIntosh, R. P. (1951). An upland forest continuum in the prairie-forest border region of Wisconsin. Ecology, 32(3), 476-496.

Dias J. E., \& Laureano, L. C. (2009). (Coord.) Farmacopeia Popular do Cerrado. (1 a ed): Articulação Pacari.

EMBRAPA, Empresa Brasileira de Pesquisa Agropecuária. Contando Ciência na Web, Bioma Cerrado. https://www.embrapa.br/contando-ciencia/biomacerrado.

Felfili, J. M., da Silva Júnior, M. C., Sevilha, A. C., Fagg, C. W., Walter, B. M. T., Nogueira, P. E., \& Rezende, A. V. (2004). Diversity, floristic and structural patterns of cerrado vegetation in Central Brazil. Plant Ecology, 175(1), 37-46.

Felfili, J. M., Carvalho, F. A., \& Haidar, R. F. (2005). Manual para o monitoramento de parcelas permanentes nos biomas Cerrado e Pantanal. Brasília: Universidade de Brasília, Departamento de engenharia florestal.

Gotelli, N. J., \& Colwell, R. K. (2001). Quantifying biodiversity: procedures and pitfalls in the measurement and comparison of species richness. Ecology letters, 4(4), 379-391.

Gutiérrez, R. M. P. (2016). Anti-inflammatory effect of birsonimadiol from seeds of Byrsonima crassifolia. Food science and biotechnology, 25(2), 561-566.

Herrera-Ruiz, M., Zamilpa, A., González-Cortazar, M., Reyes-Chilpa, R., León, E., García, M. P., \& Huerta-Reyes, M. (2011). Antidepressant effect and pharmacological evaluation of standardized extract of flavonoids from Byrsonima crassifolia. Phytomedicine, 18(14), 1255-1261.

Hiruma-Lima, C. A., Santos, L. C. D., Kushima, H., Pellizzon, C. H., Silveira, G. G., Vasconcelos, P. C. P., \& Brito, A. S. (2006). Qualea grandiflora, a Brazilian "Cerrado" medicinal plant presents an important antiulcer activity. Journal of ethnopharmacology, 104(1-2), 207-214.

Instituto Brasileiro de Geografia e Estatística. Conheça o Brasil - Território: biomas brasileiros. https://educa.ibge.gov.br/jovens/conheca-obrasil/territorio/18307-biomas-brasileiros.html.

Krebs, C. J. (2007). Ecological methodology. (2 $2^{\text {a }}$ ed), Pearson.

Lago, J. H. G., Souza, E. D., Mariane, B., Pascon, R., Vallim, M. A., Martins, R. C. C., \& Sartorelli, P. (2011). Chemical and biological evaluation of essential oils from two species of Myrtaceae-Eugenia uniflora L. and Plinia trunciflora (O. Berg) Kausel. Molecules, 16(12), 9827-9837.

Lima, T. B., Silva, O. N., Oliveira, J. T. A., Vasconcelos, I. M., Scalabrin, F. B., Rocha, T. L., \& Franco, O. L. (2010). Identification of E. dysenterica laxative peptide: A novel strategy in the treatment of chronic constipation and irritable bowel syndrome. Peptides, 31(8), $1426-1433$.

Lisita, V. C. V. (2008). Estudo de fragmentos de cerrado strictu sensu em nove empreendimentos agropecuários do noroeste de Minas Gerais. Dissertação (Mestrado em Ciências Florestais), Universidade de Brasília.

Lopes, S. D. F., Vale, V. S. D., Oliveira, A. P. D., \& Schiavini, I. (2011). Comparative Analysis Of The Structure And Floristic Composition Of Cerrado Vegetation In Central Brazil [análisis Comparativo De La Estructu Ra Y Composición Florística Del Cerrado En El Brasil Central]. Interciencia.

Lorenzi, H. \& Matos, F. J. (2008). Plantas medicinais no Brasil: nativas e exóticas. (2a ed), Plantarum. 
Magurran, A. E. (1988). Ecological diversity and its measurement. Princeton university press.

Maroni, B. C., Di Stasi, L. C., \& Machado, S. R. (2006). Plantas medicinais do cerrado de Botucatu: guia ilustrado. Unesp.

Mazzolin, L. P., Nasser, A. L. M., Moraes, T. M., Santos, R. C., Nishijima, C. M., Santos, F. V., \& Hiruma-Lima, C. A. (2010). Qualea parviflora Mart.: an integrative study to validate the gastroprotective, antidiarrheal, antihemorragic and mutagenic action. Journal of ethnopharmacology, $127(2), 508-514$.

Melo, E. T., Sales, M. C. L., \& de Oliveira, J. G. B. (2011). Aplicação do Índice de Vegetação por Diferença Normalizada (NDVI) para análise da degradação ambiental da microbacia hidrográfica do Riacho dos Cavalos, Crateús-CE. RA'EGA, 23, 520-533.

Monteiro, S. C., \& Brandelli, C. L. (2017). Farmacobotânica: Aspectos Teóricos e Aplicação. Artmed.

Obici, S., Otobone, F. J., da Silva Sela, V. R., Ishida, K., da Silva, J. C., Nakamura, C. V., \& Audi, E. A. (2008). Preliminary toxicity study of dichloromethane extract of Kielmeyera coriacea stems in mice and rats. Journal of ethnopharmacology, 115(1), 131-139.

Oliveira, S. G. D., de Moura, F. R. R., Demarco, F. F., da Silva Nascente, P., Del Pino, F. A. B., \& Lund, R. G. (2012). An ethnomedicinal survey on phytotherapy with professionals and patients from Basic Care Units in the Brazilian Unified Health System. Journal of Ethnopharmacology, 140 (2), $428-437$.

OMS. Organização Mundial de Saúde (2021). Traditional, Complementary and Integrative Medicine. http://www.who.int/medicines/areas/traditional/definitions/en/.

Pereira, A. C., \& Cunha, M. D. G. C. (2015). Medicina popular e saberes tradicionais sobre as propriedades medicinais da flora Cerradeira. Hygeia-Revista Brasileira de Geografia Médica e da Saúde, 11(21), 126-137.

Pereira, A. S., Shitsuka D. M., Parreira F. J., \& Shitsuka, R. (2019). Metodologia da pesquisa científica.

https://repositorio.ufsm.br/bitstream/handle/1/15824/Lic_Computacao_Metodologia-Pesquisa-Cientifica.pdf?sequence=1

Pinheiro, M. H. O., Ferreira, G., Cunha, M., Oliveira, H., Riul, B., \& Naves, F. (2019). A flora medicinal do Cerrado e o seu potencial fitoterápico.

Queiroz, J. (2015). Aspectos populares e científicos do uso de espécies de Eugenia como fitoterápico. Revista Fitos, 9 (2), 87-100.

Reatto, A., Martins, É. D. S., Farias, M. F. R., Silva, A. V. D., \& Carvalho Júnior, O. A. D. (2004). Mapa pedológico digital-SIG atualizado do Distrito Federal escala 1: 100.000 e uma síntese do texto explicativo. Embrapa Cerrados. https://ainfo.cnptia.embrapa.br/digital/bitstream/CPAC-2009/26344/1/doc_120.pdf.

Rêgo, A. B. D. M. L., de Souza, P. B., da Silva, R. R., \& Rêgo, P. L. (2015). Composição florística e estrutural de um componente arbóreo em área de cerrado, Paranã, TO. Revista Verde de Agroecologia e Desenvolvimento Sustentável, 10(5), 32.

Rios, J. M., Mariano, G. V. P., Silva, V. P. G. D., Santos, L. C. D. S., Costa, J. P., Zica, L. R. D. S., \& Vale, V. S. D. (2020). Comparação de análises fitossociológicas e multivariadas na determinação do grau de conservação de áreas nativas de Cerrado. Ciência Florestal, 30(3), $779-795$.

Rodrigues, V. E., \& Carvalho, D. A. (2010). Plantas Medicinais nas Florestas Semideciduais. (1 ${ }^{\text {a }}$ ed), Universidade Federal de Lavras-UFLA.

Sampaio, A. C. F., Bianchin, J. E., Santos, P. M., Ariati, V., \& Santos, L. M. (2018). Fitossociologia do Cerrado sensu stricto na bacia do Rio Parnaíba no nordeste brasileiro. Advances in Forestry Science, 5(2), 299-307.

Santana, E. C. (2017). Atividade antioxidante, antimicrobiana e caracterização de compostos bioativos da casca interna de kielmeyera coriacea mart. \& zucc. Dissertação (mestrado). Programa de Pós-graduação em Química. Universidade Federal de Uberlândia.

Schilling, A. C. (2012). Ausência de Estabilização da Curva de Acumulação de Espécies em Florestas Tropicais. Ciênc. Florest, 22 (1), 101-111.

Senigalia, R. L. C., de Souza Ferreira, A. L., Kratz, D., Coelho, M. D. F. B., dos Santos, A. S. R. M., \& Castro, D. A. (2020). Toxicidade de extratos vegetais de plantas do cerrado de uso medicinal. Brazilian Journal of Development, 6(8), 55308-55317.

SFB, Serviço Florestal Brasileiro (2019). Manual de campo: procedimentos para coleta de dados biofísicos e socioambientais. Manual de Campo-Inventário Florestal Nacional, 2 (1).

Silva, M. C. (2012). 100 árvores do Cerrado: sentido restrito - guia de campo. Rede de Sementes do Cerrado.

Silva, A. F., Rabelo, M. F. R., \& Enoque, M. M. (2015). Diversidade de angiospermas e espécies medicinais de uma área de Cerrado. Revista Brasileira de Plantas Medicinais, 17(4), 1016-1030.

Silva, F. A. M., Evangelista, B. A., Malaquias, J. V., de Oliveira, A. D., \& Muller, A. G. (2017). Análise temporal de variáveis climáticas monitoradas entre 1974 e 2013 na estação principal da Embrapa Cerrados. Embrapa Cerrados-Boletim de Pesquisa e Desenvolvimento (INFOTECA-E).

Strassburg, B. B., Brooks, T., Feltran-Barbieri, R., Iribarrem, A., Crouzeilles, R., Loyola, R., \& Balmford, A. (2017). Moment of truth for the Cerrado hotspot. Nature Ecology \& Evolution, 1(4), 1-3.

Vieira, L. S., Sousa, R. S., \& Lemos, J. R. (2015). Plantas medicinais conhecidas por especialistas locais de uma comunidade rural maranhense. Revista Brasileira de Plantas Medicinais, 17(4), 1061-1068.

Vilarinho, C., \& Garcia, M. (2017). Plantas medicinais: o ouro do nosso cerrado. Kelps.

Zeni, A. L. B., Parisotto, A. V., Mattos, G., \& Helena, E. T. D. S. (2017). Utilização de plantas medicinais como remédio caseiro na Atenção Primária em Blumenau, Santa Catarina, Brasil. Ciência \& Saúde Coletiva, 22, 2703-2712. 